\title{
SOFTWARE FOR VIRTUAL ENVIRONMENT IN ECONOMIC SCIENCES
}

\author{
Associate Professor dr. Veronica Ştefan, veronica.stefan@ats.com.ro \\ Valahia University of Târgovişte
}

\begin{abstract}
Over several million years, humans have learned from other humans, by speech, action and observation. It can be strongly argued that this is hard-wired into our genes, as the survival advantages of communication and learning from each other are obvious. In the last few decades, a new and fundamentally different form of learning has emerged. The successful electronic delivery of learning material is very hard, much harder than the traditional method. It requires new forms of thought and a great deal of attention to detail such as colors and sounds. Electronic delivery also requires a level of sensory stimulation, such as a combination of visual and audio, which is consistent with traditional modes of learning. This paper intend to prove that also the newest and advanced methods, as Web 3D and Virtual Reality can be accessible for the economic sciences teaching, through a new friendly tools software and interfaces. After briefly presenting the main Web3D technologies, we summarized the pedagogical basis that motivate their exploitation in the context of education and highlighted their interesting features. We outline the main positive results obtained in economic sciences teaching so far, and point out some of the current and futures research directions.
\end{abstract}

Keywords: Knowledge transfer, 3D Simulation, Web design, Web 3D, eLearning applications

\section{Introduction}

Learning based knowledge transfer is becoming more and more a field of research which deserves the entire attention of the research community, regardless of their domain of expertise, especially because of large scale usage of advanced technologies such as artificial intelligence, web technologies, virtual reality modeling languages and simulation techniques.

In the context of globalize communication, this characteristic is becoming more provocative through the possibility of creating a collaborative space using specific methods that allow the creation of a virtual learning space. When these technologies work together and converge through the use of open source development of standard unified tools, there is a significant potential of obtaining spectacular results for improving learning techniques and assimilating knowledge.

The user of the new society based on knowledge is any person that wishes to be educated, in a certain field, according to his level of knowledge or cognitive needs in a certain context..

The next step is an approach oriented on the pedagogical dimension, as the development and the utilization of the educational modeling languages. From the pedagogical aspects to the technological ones, the research theme is a very actual theme, having an interdisciplinary character and being necessary in the context of the Web 2.0. technologies development. The eLearning has known a spectacular evolution, going from a quantitative development (there are universities and firms that offer "on-line" courses) to a qualitative one, through the involvement of the international standardization organisms and the elaboration of quality criteria.

The objective of this paper is to transfer this type of solutions in other fields of training, such as the development of information technology systems in economics (for example in presenting a 
virtual space for the organization chart and the document workflow, virtual visualization for statistical data, simulation of the financial processes for reducing risks or maximized the results), and integration with other types of methods and technologies.

We will try to give a substantiated answer to a part of the questions related to the most advanced technologies in the field, new research directions, the future of solutions for creating visual learning demonstration components, integrating them into distributed web applications and thus creating not only a scientific workspace, but also a collaborative one.

\section{Standards for e-Learning}

The standards of e-Learning represent technical protocols that encourage an easy transfer of data between systems that are based on different technologies. The e-Learning standards mean adopting, opening and crediting these technologies in such a manner that will enable the creation, administration and spreading of teaching in a consistent long standing way. Without using these standards there is no possible inter-change or re-usage of teaching methods.

The standards that lie at the core of the e-Learning activities are based on specifications produced and developed by experts in the field of industry and education. Specifications are much more applicable in the field of research work and software development.

Currently there are four groups that guide the development of e-Learning standards [5]:

1. AICC/CMI - created a guide in constructing the content of teaching units (i.e. the objects of training), communicated along with a learning management system. These standards were founded in 1988 (www.aicc.org/pages/aicc_ts.htm);

2. ADL/SCORM - defined the way in which the contents of the teaching units can interact within other systems (www.adlnet.gov);

3. IMS - developed a guide to help labeling, testing and packing the content of the meta-data (www.imsglobal.org);

4. ARIADNE - was created by a group of universities within the European Community and Switzerland. ARIADNE is not exactly a training system, but an environment in which the development, the management and the usage of educational materials with various contents is facilitated (www.ariadne-eu.org).

Implementing the e-Learning standards involved the following challenges:

- Technical standards for successful independent platforms;

- A category of systems necessary in classifying an easy-to-access content;

- Standards used in administration and follow-up of the training materials;

- Standards used in evaluating and testing those who are being trained;

- Systems that monitor students and their evolution;

- Systems for protections the rights of the intellectual property;

- Supplying various necessary contents in the educational process.

\section{Toward Web 3D solution. Content Authoring tools and Software development}

No matter the expertise they have, all teachers must identify the best and most modern methods of teaching using diverse means from Powerpoint slides to 2D graphics, 3D visualizations and simulations, Web transmission and access. The Internet can be used as a viable source of examples that those interested can adapt, upgrade and use and then they can make them available for other users and developers of such applications in the future [17].

The inventory and the classification of the software technologies and architectures, as well as of the main types of graphical and design software applications that can be created using these means is extremely important. 
Computer Graphics and human-computer interaction (HCI) could cover areas like: raster graphics, vector graphics, HTML basics, graphic design basics, web design and multimedia, 3D modeling and animation, virtual reality, compositing, broadcast design. Within these categories, the development of Web 3D applications is the most important due to the benefits it creates.

The virtual space created by the 3D brings advantages such as increased motivation on behalf of the student and increased efficiency in explaining difficult concepts. There are fields such as medicine where the Web 3D applications have proved their utility sooner, while in other fields there haven't been identifies applicable ideas yet, which doesn't mean they are not as usefully or that in the future there shall not be identified solutions to express their utility.

\subsection{The categories identified in Web 3D Applications}

The $3 \mathrm{D}$ vision and visualization, attractiveness and efficiency in carrying out the didactic material, sustains the transition from eLearning to Web 3D learning that included also the virtual and collaborative notions. Beside the category of $3 \mathrm{D}$ applications, creating graphical applications for eLearning involves using different types of software, depending on how much they incorporate or not Web technologies or other components of design, modeling and simulation, out oh witch [2]:

- Web 3D programming languages: Java Script, VRML, X3D;

- Web 3D modeling tools: Maya, 3ds max, Bezier, NURBS; Solidworks, ArchiCAD;

- 3D Authoring tools: X3D Edit, Flux Studio, Bitmanagement, Flux Player, Subdo;

- Visualizations, documentations and simulations in 2D: Mathlab, Solver, Extend, Visual Architect, Labview, Arena, Camtasia;

- Web development and design: HTML, XML, ASP, PHP, Java Script;

- Web modeling tools: Flash, DreamWeaver, Adobe (Premiere, Illustrator, Photoshop;)

- OpenGL (Graphics Library); an industrial standard programming language;

- Haptic in educational application;

- Augmented reality.

\subsection{Traditional Web-based programming languages}

Probably not much to say here, just that the existing languages like HTML and the more robust XML (eXtended Markup Language) will continue to find uses in the implementation of 3D Web-based sites. Merging text, animation, sound and 3D content can be done using these standards. Java Server Pages (JSP), Active Server Pages (ASP) as well as PHP can be used to provide the necessary functionality on different architectures from client-server to n-tire [6,7].

\subsection{Web 3D standards and programming languages}

X3D (Web3D Consortium, 2006, [10]) is an ISO standard with an open architecture and a rich range of capabilities for real-time graphics processing that is employed in a wide array of domains and user applications. A successor to VRML, X3D is being developed by the Web3D Consortium as a refined standard [1]. 

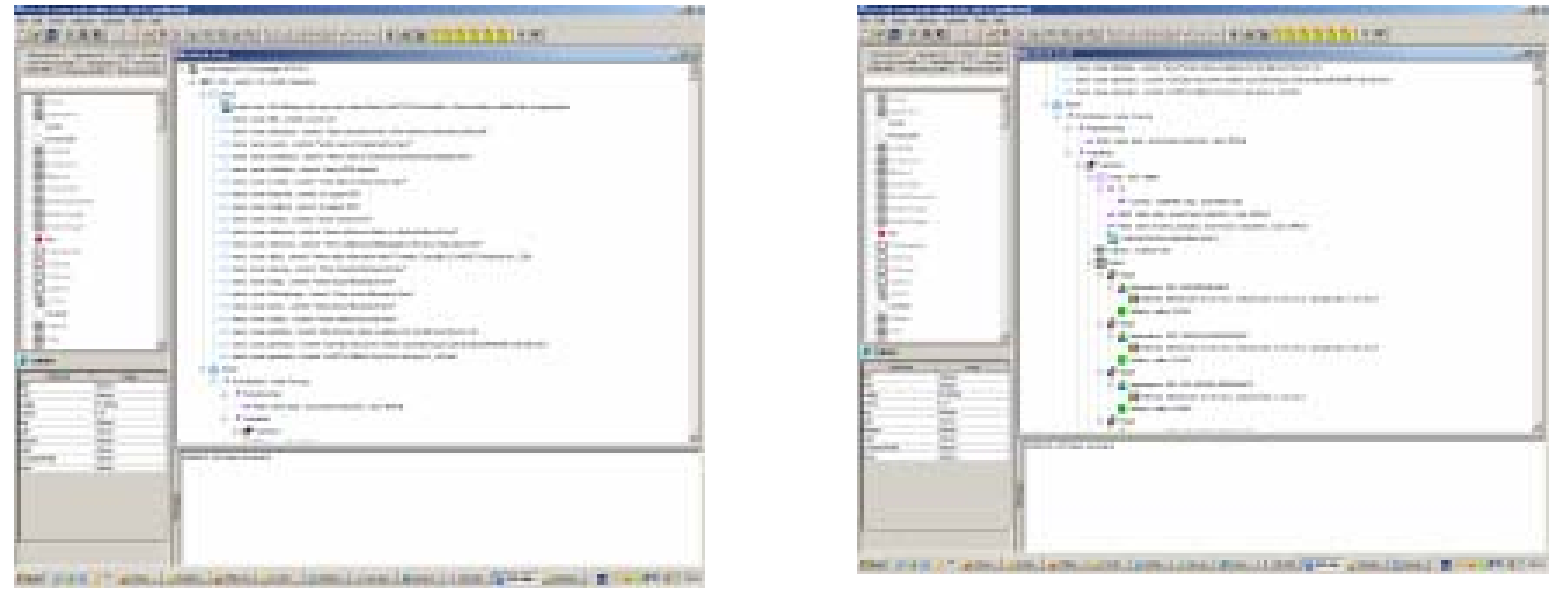

Figure 1, 2. X3D Web editor importing VRML code and executing as X3D

\subsection{Content development tools for 3D}

Maya ${ }^{\mathbf{T M}}$ is one of the world's leading innovators of 3D graphics modeling technology. In 2003, the company was awarded an Oscar for Technical Achievement from the Academy of Motion Picture Arts and Sciences for its development of Maya software, its professional 3D animation and effects package.

A particular category of applications are those that allow virtual exploration of certain spaces, such as museums (see Virtual Museum project at http://www.cgg.cvut.cz/vsp/), cities (Virtual heart of central Europe at http://www.sccg.sk/ projects/virtual-heart/ ), but also production plants or institutions, architecture of certain devices with the purpose of allowing and facilitating the understanding of the way in which some entities are organized or how some technical equipment function.

Another prominent modeling software is SolidWorks ${ }^{\text {MM }}$ [15]. It allows development of 3D models and rapid prototyping of 3D shapes from 2D CAD drawings. With the newest component $3 D$ Instant Website it provide a step forward in 3D design communication via the web, allowing to publish the designs instantly and to communicate with an entire work team, other designers, manufacturing staff, marketing management, purchasing agents, suppliers and customers.

$3 D$ Instant Website is a power tool that provides interactive and 3D models they can view, rotate, zoom, and pan without having to buy CAD software or install special viewers, no web server and no additional software needed. The popular e-Drawings file format offers drawing interpretation tools including 3D cross hair, animation, hyperlinked views, virtual folding and zooming/panning. 


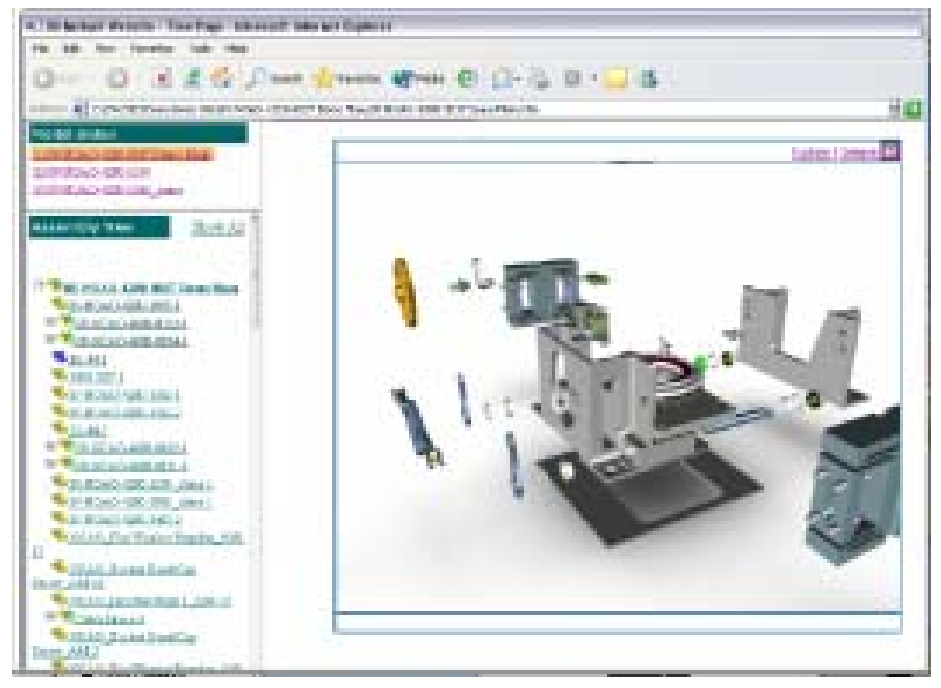

Figure 4. SolidWorks application in conjunction with the Web

MaxScript is the built-in scripting language for $3 d \boldsymbol{d}$ Max [14], an other modeling software. This language provides users to program most of the aspects of $3 \mathrm{ds}$ Max program usage and to use these scripts with different input parameters. User can control program flow interactively through MaxScript Listener window. Scripts can be placed in 3ds Max Utility panel or installed as program desktop buttons. MaxScript is an object oriented programming language and works with objects and classes. There is a lot of embeded classes arranged into a hierarchy of inheritance, this meaning that a class inherits operations and properties of parent classes. MAXScript provides users of $3 \mathrm{ds}$ Max with the ability to:

- Script most aspects of the program's use, such as modeling, animation, materials, rendering;

- Control the program interactively through the command-line Listener window;

- Package scripts within custom Utility panel or modeless windows for a standard user interface;

- Package scripts as a macro, and install these macro scripts as buttons in the product's toolbars;

- Extend or replace the user interface for objects, modifiers, materials, textures, render effects;

- Build scripted plug-ins for custom objects, modifiers and render effects;

- Build custom import/export tools using the built-in file I/O.

\subsection{Web 3D Authoring Tools and Plug-ins}

The X3D based web pages need a special plug-in to be installed in the web browser $[4,8,9]$. This plugin is an X3D content player. Several companies offer X3D player implementations for free or on a license- based.

The Bitmanagement Contact X3D Player [11] is one of the best implementations (based on the number of bugs) that we have found so far on the market currently (screenshot in Figure 5). Another X3D player "Flux Player" is developed by Media Machines [12]. The company developes also an X3D authoring tool called "Flux Studio" (Figure 6). 

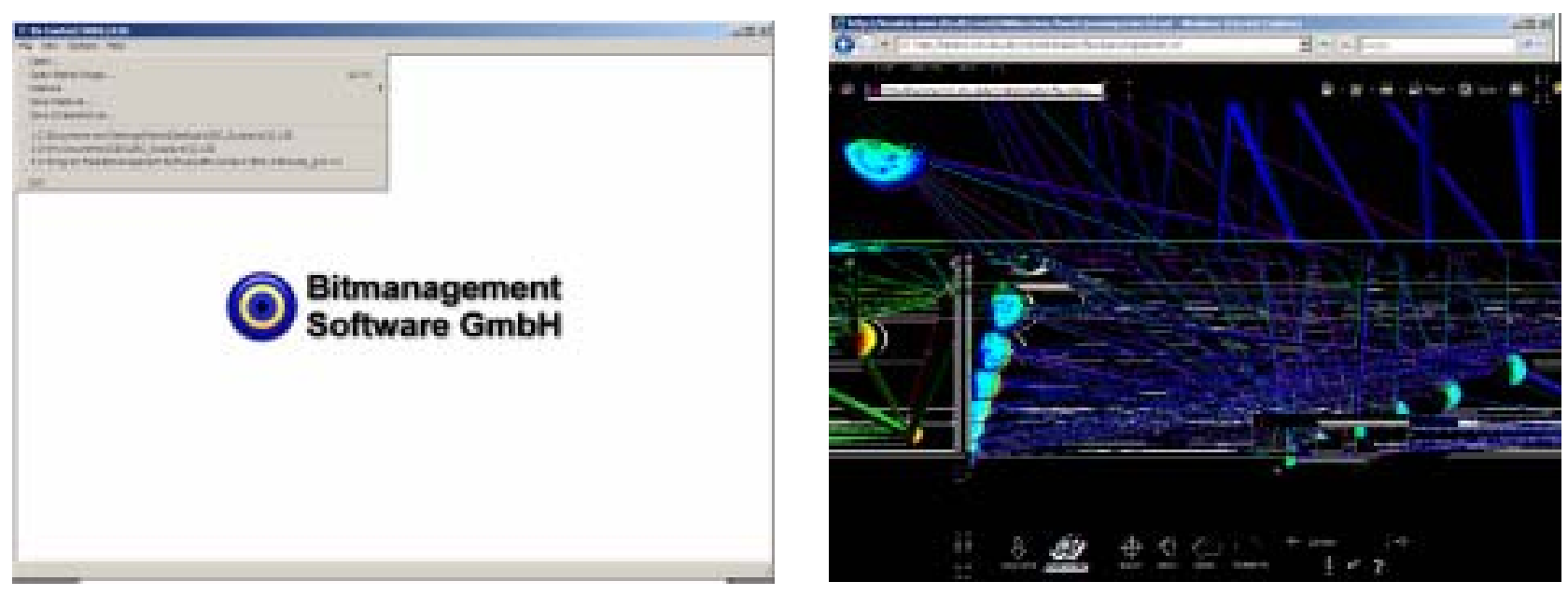

Figure 5, 6. Contact X3D Player and Flux Studio Player

\section{Web 3D in Economics: 3D for Financial Markets and Forecasting}

The promise of computers has always been their ability to extend the capacity of human mental processes. Nowhere is that promise more fully realized than in neural networks and in no field are the implications of greater economic significance than finance and applicability of neural networks in the financial world [5]. Distinct methodologies are given to solve different problems encountered in the financial world [3]. Numerous examples are treated as credit risk assessment, estimation of stock market indices, portfolio management.

Asset and portfolio managers, market makers, stock traders, market advisers deal with an overwhelming amount of information on a daily and hourly basis. The financial market analysts and traders need better tools that give a single point of reference to provide critical information that matters the most in stock analytics. Real time stock data of the interest consists of 10 's to 100 's symbols that should be followed in time and relationship with other important market factors. Large quantities of numerical data are virtually impossible to understand quickly and accurately unless one uses some sophisticated software tools to do this.

Until very recently the 3D was exclusively used by professionals (movie makers, web designers, etc.). Now it is possible to realize the scientific graphics to be easy used for money trader or stock market adviser, who can not afford spending much time playing around with PC, but rather needs a tool to make money in his practical situation. By example, the 3DStock software from ScienceGl Company [18] can be used to help money maker to get immediately productive. The general concepts of the visualization are as follows from figure 10 and 11 below:
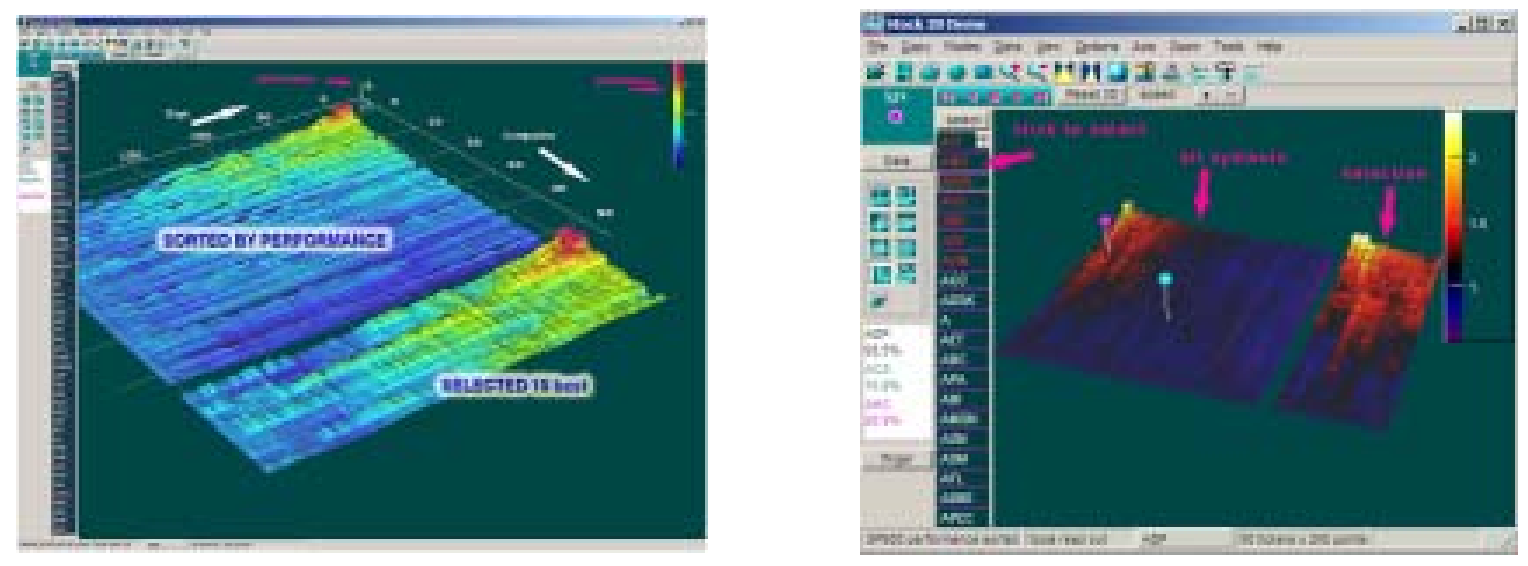
Each company is represented as "tape" drawn in direction of Date/Time. There are 2 surfaces available, one is the full data loaded and second is the default selection of 10 best performing symbols. The selection can be made with left side list of all symbols loaded. The height of the tape is proportional to normalized performance of the symbol. For easy perception the performance of symbols is colored with palette. Advantage of $3 \mathrm{D}$ visualization is that you can immediately evaluate performance of multiple symbols in one screen. In example above it is 50 companies in main surface and 10 companies in selection surface. According to the palette best performing tickers are colored as red, while medium as yellow (cyan), worst as dark blue. After general evaluation it can drill down the data by moving mouse or 3D pins within any point of interest, as date/time for any company.

Also a $\boldsymbol{E} \boldsymbol{U}$-funded BeinGRID project can be count for the solution in financial sector. Financial institutions face computational time and resource challenges in the risk analysis of investment portfolios and these real-time financial algorithms, which use stock market and trading desk data, impose real-time processing constraints which are a major challenge for the Grid. An exemple for colaborative work using Grid solution and Web technologies is the project BE11 - Risk Management in Finance [16]. The business objective is to demonstrate how grid technologies can bring solutions to challenges financial institutions have to face.

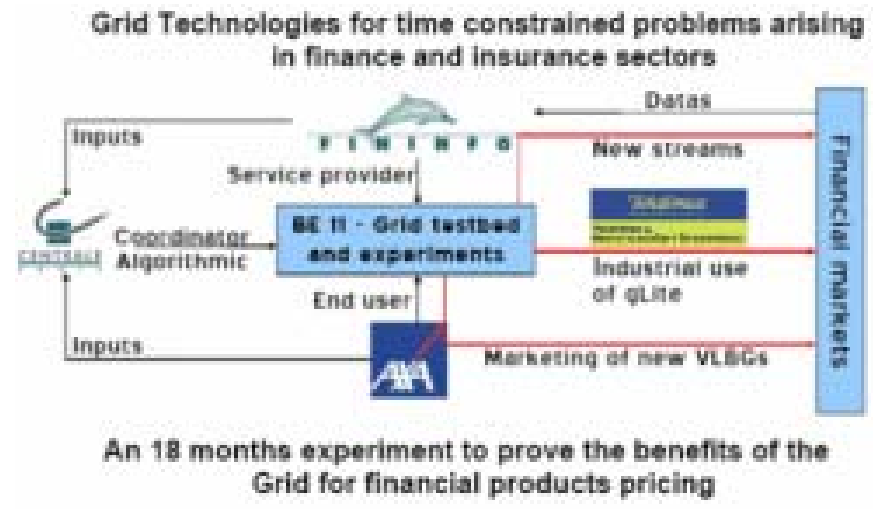

Figure 12. The Project BeingGRID "Risk management in Finance"

Agent-based simulation is a research method often applied in economics [13].

This method gives the possibilities of modeling artificial economic life by use of the MUD (Multi User Domain) framework. In the virtual world provided by the MUD, actors are controlled by human user input, or by programs. Users connect to the virtual reality via Telnet. This makes it possible to distribute the simulation of the virtual reality and of the actors among several hosts.

The simulation of economic agents describes two approaches, the steepest ascend optimization and a more "human- like" decision algorithm using the concept of bounded rationality.

It is necessary to describe a plan to modify a MUD system to act as a platform for such simulation. The MUD is amended so that it facilitates economic transactions between players, but 
instead of human players, the world is populated with artificial agents. Established algorithms are used to implement the behavior of these agents. Human players can be used as well, either as observers or as part of the simulation. It seems to be work in progress that was never finished.

\section{Conclusion}

The advantages of using computers and the Internet as tools for research, communication and development of creativity in education, as well as a solution for increasing the attractiveness of the classes and for stimulating the interest of young people for study are long back proven.

This paper demonstrates how the most advanced and sophisticated IT\&C tools and the field of Web 3D and Virtual Reality can be accessible for those interested people, involved in the transfer of knowledge and science using Web technologies and friendly tools and interfaces. The paper also highlights the possibilities of accessing and using these technologies in economic sciences educational fields. Taking over the tasks of creating electronic educational content from specialized companies by the teachers themselves, will allow the educational system not only to benefit from the advantage of an elaborate and attractive scientific content, but also from the fundamental emotional and motivational element of learning that no matter how elaborated and technically advanced the lessons are, the role of the teacher cannot be replaced.

Teaching in a Knowledge Society involves focusing the didactic process on the student, introducing and using the ICT solutions in education. In June 2007 the Ministry of Information and Communication Technologies has organized a seminary [23] dedicated to drawing up a document of public policy regarding the integration of the ICT tools in schools, named " Key competences for a knowledge base society: the role of ICT".

The capacity of the didactic personnel to work with the tools of the information and communication technologies must become a standard. The educational system must establish long term partnerships with various companies from different fields of activity so that the students and the teachers can get accustomed with the challenges of the labor market.

It is absolute reality that fact that more an more educational site appear on the market $[19,20,21,22]$. Their utility is obvious and they create a new method of working for pupils, students and teachers. According to the expert estimations, new competences shall be developed for teachers, so that in the following three years, over 60.000 teachers shall be able to benefit of training within the Intel®Teach program - Teaching in a Knowledge-based Society.

We can conclude that, by using the Internet and the Web technologies as digital means for virtualization and retransmission, as well as the software means of expression to create multimedia applications, of graphical design and of 2D or 3D simulation, each of the users benefit of knowledge resources and at the same time he transmits the knowledge in an environment which theoretically has no limits in space, time or as auditory.

This represents an additional reason for every user to be an actor that is aware of his role as a beneficiary, but also as a creator of knowledge that contributes as a particular inference engine to the construction of the Mankind's Global Expert System of Knowledge. The technical means and the expertise exists, but we just need to be aware, to be motivated and to act together.

\section{Bibliography:}

\section{Books:}


[1] Don Brutzman, Leonard Daly: (2007): “X3D: Extensible 3D Graphics for Web Authors", Morgan Kaufmann Publishers, 2007

[2]Veronica Stefan, "Tehnologii orientate obiect pentru baze de date relationale", Editura

Infomega, Bucuresti 2006, $289 \mathrm{pg}$.

\section{Conference Proceedings:}

[3] Firescu V., Stefan V., (2007): “Instruments financiers et marchés financiers “,55ème Congrès AIELF 2007-Varsovie, 21-24 May

[4] Hamza-Lup F.G., Sopin Ivan and Zeidan Omar: (2007): "Towards 3D Web-based Simulation and Training Systems for Radiation Oncology", ADVANCE Magazine for Imaging and Oncology Administrators, Vol.17 (7), July 2007.

[5] Hamza-Lup Felix G., STEFAN Veronica (2007), "Web 3D \& Virtual Reality - Based Applications For Simulation and e-Learning", The 2nd International Conference on Virtual Learning - ICVL 2007, October 26-27, Bucharest University Press, pg. 71-80, ISBN 978-973737-380-9

[6] Stefan V., (2007):“La contribution des systemes informatique d'interface dans la création d'un espace collaboratif dans l'UE élargie “, EUCONF 2007 18-21 April, Rijeka, Croatia [7] Veronica Stefan, "Tehnologii de interoperabilitate pe Web pentru servicii online", Revista Tribuna Economică 38-39, Bucureşti 2006, ISSN 1018-0451,

\section{Internet Sources:}

[8] http://www.cs.armstrong.edu/felix/html/research.html

[9] http://www.hyperion.armstrong.edu

[10] http://www.web3d.org

[11] http://www.bitmanagement.com

[12] http://www.mediamachines.com

[13] http://phet.colorado.edu/web-pages/simulations-base.html

[14] http://www.the3dstudio.com/product_details.aspx?id_product=3393

[15] http://www.solidworks.com

[16] http://www.beingrid.com/

[17] http://en.wikipedia.org/wiki/Web_2

[18] http://www.scienceGL.com

[19] http://www.timsoft.ro:80/index.php?pagina=resurse2

[20] http://www.academiaonline.ro/

[21] http://www.elearning.ro

[22] http://www.didactic.ro/

[23] http://www.mcti.ro 